\title{
Precision medicine: PI3K targeting in advanced breast cancer
}

\author{
Andrea Rocca ${ }^{1}\left[\right.$ - Elisabetta Melegari ${ }^{1} \cdot$ Michela Palleschi $^{1}$
}

Received: 6 August 2019 / Accepted: 12 August 2019 / Published online: 19 August 2019

o) Springer Science+Business Media, LLC, part of Springer Nature 2019

The remarkable results obtained by adding alpelisib to fulvestrant in patients with hormone receptor-positive, HER2negative, PIK3CA-mutant advanced breast cancer represent an important step forward in precision cancer medicine [1]. Nonetheless, they raise further issues on what is the appropriate tumor molecular characterization to improve drug response prediction.

Not all patients with PIK3CA-mutant breast cancer benefit from alpelisib, and perhaps some patients with PIK3CA wild-type cancer might benefit, although results in the cohort without PIK3CA mutation are far from being statistically significant. Different PIK3CA mutations have different biological impacts, but other molecular alterations are also likely responsible for these facts. As the authors point out, loss of PTEN is a known mechanism behind resistance to PI3K $\alpha$ inhibitors [2], mediated by PI3K $\beta$ activation. PTEN loss can coexist with PIK3CA mutations in treatment-naïve patients [3], potentially affecting their responsiveness to PI3K inhibitors. Coexisting alterations in other nodes of PI3K-AKT-mTOR pathway, and in other pathways like the Cyclin D-CDK4/6-Rb pathway, are also involved. Furthering precision medicine will likely require dealing more deeply with the molecular complexity of each single cancer.

Author contributions Andrea Rocca, Elisabetta Melegari and Palleschi Michela conceived the study and wrote the letter.

\section{Compliance with ethical standards}

Conflict of interest Andrea Rocca declares to have received two fees from two advisory boards: one for a total of $400 €$ and the other of 800 $€$ (respectively, Novartis and Pfizer). Elisabetta Melegari and Michela Palleschi declare that they have no conflict of interest.

Ethical approval This article does not contain any studies with human participants or animals performed by any of the authors.

\section{References}

1. André F, Ciruelos E, Rubovszky G, Campone M, Loibl S, Rugo HS, Iwata H, Conte P, Mayer IA, Kaufman B, Yamashita T, Lu YS, Inoue K, Takahashi M, Pápai Z, Longin AS, Mills D, Wilke C, Hirawat S, Juric D, SOLAR-1 study group (2019) Alpelisib for PIK3CA-Mutated, hormone receptor-positive advanced breast cancer. N Engl J Med 380(20):1929-1940

2. Juric D, Castel P, Griffith M, Griffith OL, Won HH, Ellis H, Ebbesen SH, Ainscough BJ, Ramu A, Iyer G, Shah RH, Huynh T, Mino-Kenudson M, Sgroi D, Isakoff S, Thabet A, Elamine L, Solit DB, Lowe SW, Quadt C, Peters M, Derti A, Schegel R, Huang A, Mardis ER, Berger MF, Baselga J, Scaltriti M (2015) Convergent loss of PTEN leads to clinical resistance to a PI(3)K $\alpha$ inhibitor. Nature 518(7538):240-244

3. Stemke-Hale K, Gonzalez-Angulo AM, Lluch A, Neve RM, Kuo WL, Davies M, Carey M, Hu Z, Guan Y, Sahin A, Symmans WF, Pusztai L, Nolden LK, Horlings H, Berns K, Hung MC, van de Vijver MJ, Valero V, Gray JW, Bernards R, Mills GB, Hennessy BT (2008) An integrative genomic and proteomic analysis of PIK3CA, PTEN, and AKT mutations in breast cancer. Cancer Res 68(15):6084-6091

Publisher's Note Springer Nature remains neutral with regard to jurisdictional claims in published maps and institutional affiliations.
Andrea Rocca

andrea.rocca@irst.emr.it

1 Istituto Scientifico Romagnolo per lo Studio e la Cura dei Tumori (IRST) IRCCS, Meldola, Italy 